\title{
THE LICENSING DILEMMA: UNDERSTANDING THE DETERMINANTS OF THE RATE OF TECHNOLOGY LICENSING
}

\author{
ANDREA FOSFURI* \\ Department of Business Administration, Universidad Carlos III de Madrid, Madrid, \\ Spain
}

\begin{abstract}
The licensing of technology entails a trade-off: licensing payments net of transaction costs (revenue effect) must be balanced against the lower price-cost margin and/or reduced market share implied by increased competition (profit dissipation effect) from the licensee. We argue that the presence of multiple technology holders, which compete in the market for technology, changes such a trade-off and triggers more aggressive licensing behavior. To test our theory, we analyze technology licensing by large chemical firms during the period 1986-96 for 107 chemical products. We find that the rate of technology licensing displays an inverted $U$-shaped relationship with the number of potential technology suppliers and is negatively related to the licensor's market share and to the degree of technology-specific product differentiation.
\end{abstract}

\section{INTRODUCTION}

The last two decades have witnessed an unprecedented growth in a variety of arrangements for the exchange of technologies and technological services (Rivette and Kline, 1999; Rigby and Zook, 2002). In the United States alone, technology licensing revenues are estimated to account for U.S. $\$ 45$ billion annually; worldwide, the figure is around U.S. $\$ 100$ billion (The Economist, 2005). The biopharmaceutics, software, semiconductor and telecommunications sectors have made the licensing of intellectual property a way of life.

It is not surprising that small technology-based firms license their intellectual property. Lacking the downstream manufacturing, distribution, and marketing capabilities, they have no other means

Keywords: licensing; revenue effect; profit dissipation effect; chemical industry

* Correspondence to: Andrea Fosfuri, Department of Business Administration, Universidad Carlos III de Madrid, Calle Madrid, 126, 28903 Getafe, Madrid, Spain.

E-mail: fosfuri@emp.uc3m.es of appropriating returns from innovation. More surprising is the active promotion of licensingbased strategies by large, established producers. Firms such as Union Carbide, Procter \& Gamble, DuPont, Boeing, Hoechst, IBM, Texas Instruments, AT\&T, and Phillips Petroleum are now explicitly considering licensing revenues as a part of the overall return from their technological investments (Rivette and Kline, 1999). These firms are well established, have large market shares in the product markets, and are capable of exploiting the technology on their own.

This paper examines the licensing strategies of large firms by focusing on some of the determinants of their rate of technology licensing. In particular, we aim to shed light on the relationship between competition in the market for technology and the licensing decisions of firms. We argue that a firm's rate of technology licensing can be explained by the interplay of two effects that licensing produces on the licensor's profits: the profit dissipation effect and the revenue effect (Arora and Fosfuri, 2003). Indeed, technology 
licensing forces a trade-off: licensing and royalty revenues net of transaction costs (the revenue effect) must be balanced against the lower price-cost margin and/or reduced market share implied by increased competition (the profit dissipation effect) from the licensee. The presence of multiple technology holders, which compete in the market for technology, changes such a trade-off and triggers more aggressive licensing behavior. We then focus on two other potentially important determinants of a firm's rate of technology licensing: the licensor's market share in the product market and the degree of technology-specific product differentiation.

We test our theory on a sample of large chemical firms that possess technological competencies in a set of 107 chemical products by examining their licensing strategies over the period 1986-96. The chemical industry has a long tradition of technology licensing (Arora, 1997) that allows us to gather reliable data. In addition, as we highlight in the next section, there are often several technologies available from different licensors to produce the same chemical product, which helps us to underscore the effect of competition in the market for technology. There is an established market for polyolefin production processes, for instance, with about 25 polyethylene and 8 polypropylene technologies available. Large, established chemical producers like Dow Chemicals, BP-Amoco, Exxon-Mobil, Union Carbide, Univation, and Basell, along with independent technology suppliers like Novolen and Engelhard, compete face to face in the licensing market (Tullo, 2003).

This research contributes to several streams of the licensing literature. First, using concepts from economic theory, we build a simple framework that helps us to predict empirically a firm's rate of technology licensing. It goes beyond the standard transaction costs theory used in the management literature to explain why licensing is or is not chosen for a given transaction (Williamson, 1991; Teece, 1986, 1988). We follow an approach that considers the impact of licensing on the whole value chain of the licensor rather than narrowly focusing on economizing on every single transaction. Needless to say, transaction cost considerations are still important in shaping a firm's licensing strategy. Hence, our approach complements rather than substitutes the extant transaction costs theory.
Second, and most important, this work contributes to the relatively underdeveloped empirical research on licensing. This lacuna is understandable. In many industries, licensing is a recent phenomenon, so available data are scattered. In addition, firms tend to conceal information about licensing deals, which are typically considered to be strategic decisions that are not publicly disclosed.

Anand and Khanna (2000a) provide one of the few econometric investigations of the rate of licensing. Their study is aggregated at the level of the sector, and they do not attempt to explain inter-firm differences in the rate of technology licensing. Arora and Ceccagnoli (2006) analyze how patent effectiveness affects a firm's patenting behavior and its propensity to license. They do not look, however, at the interaction between licensing decisions and competition in the market for technology, which is crucial in this paper. Recently, several scholars have directed their attention to the analysis of licensing practices by universities (Mowery and Shane, 2002). For instance, Sine, Shane, and Di Gregorio (2003) have shown that the rate of licensing by universities is an increasing function of their prestige. However, university licensing decisions differ considerably from those made by large firms, primarily because universities do not have stakes in the product market. ${ }^{1}$

Other empirical research on technology transfer has focused on the factors that determine a firm's choices among various organizational forms (e.g., Teece, 1986; Hill, 1992). For instance, Gans, Hsu, and Stern (2002) study the determinants of commercialization strategy for start-up innovators. Within this tradition, the empirical literature has paid particular attention to foreign market entry choices (e.g., Kogut and Singh, 1988; Hill, Hwang, and Kim, 1990). None of these studies investigated the factors underpinning the rate of technology licensing among firms.

The remainder of the paper is organized as follows. The next section briefly discusses licensing dynamics in two chemical products and explains the motivation behind our interest in the role of competition in the market for technology. Then,

\footnotetext{
${ }^{1}$ In the strategy literature, a great deal of research has been devoted to the analysis of alliances (e.g., Dussauge, Garette, and Mitchell, 2000). Although licensing could be considered as a special type of alliance, the evidence has shown that licensing contracts behave quite differently, and therefore deserve ad hoc attention (Anand and Khanna, 2000b).
} 
the article develops the theoretical framework for explaining the rate of technology licensing among firms and formulates some testable hypotheses. The description of the empirical methodology and data is followed by a discussion of the results and the overall conclusions.

\section{TECHNOLOGY LICENSING IN THE CHEMICAL INDUSTRY}

Technology licensing in the chemical industry has a long tradition. Cross-licensing agreements were already being used at the beginning of the 20th century as a means of maintaining market shares and deterring entry into an international chemical market characterized by the presence of strong cartels (e.g., Arora, 1997). It was only after World War II, however, that firms started to use licensing to profit from innovation, and a market for chemical technology began to arise. Beginning in the 1950s, an increasing number of chemical processes became available for licensing. In this section, we briefly describe licensing dynamics in two chemical markets, highlighting the role played by competition in the technology market in shaping the licensing strategies of firms. ${ }^{2}$

\section{Acrylic acid}

Acrylic acid is a common chemical compound, and the key ingredient in many household products: paints, textiles, adhesives, plastics, and detergents, for example. Although first prepared in 1843, it was not until the late 1920s that acrylic acid was produced commercially and not until the early 1950s that it was used in any major way. Several processes - acetylene-based, acrylonitrile hydrolysis, ketene process, ethylene cyanohydrin process - were employed to produce acrylic acid prior to the 1970s, when Nippon Shokubai, a Japanese chemical firm, developed the standard technology based on propylene oxidation. Until the mid 1980s, Nippon Shokubai licensed its technology, which was also available through another Japanese firm, Mitsubishi Chemicals, but other technology holders, like the German giant BASF, did not. In recent times, however, all the potential licensors

\footnotetext{
${ }^{2}$ These two short case studies have been constructed using information assembled from a variety of sources, most notably specialized chemical journals, the business press, and the Internet.
}

are also producers, with symmetric stakes in the acrylic acid market and a strong interest in maintaining market stability. Thus the attitude toward licensing has become more conservative, even among Nippon Shokubai and Mitsubishi Chemicals, as firms tend to avoid direct and potentially destructive competition in the licensing business. Most licensing is now directed at markets with strong growth potential that could not be reached by any other means. Hence, a sort of tacit collusion in the market for acrylic acid technology seems to be in place nowadays. ${ }^{3}$

\section{Ethylene glycol}

Ethylene glycol is a clear, colorless, odorless, viscous liquid with a sweet taste that can produce dramatic toxicity. It is commonly found in antifreeze, automotive cooling systems, and hydraulic brake fluids and is used in industrial settings as a solvent and as raw material in a variety of processes.

Although ethylene glycol was prepared as early as 1856 , it was not until the 1920 s that the U.S. firm, Union Carbide, began commercial production. The dominant technology for producing ethylene oxide is currently the direct oxidation of ethylene, a process developed by a French firm at the beginning of the 1930s and subsequently perfected by Union Carbide. By the end of the 1940s, two other companies-Shell and the engineering firm Scientific Design-had developed new technologies based on the oxidation of ethylene. Other technologies have been tried and abandoned by such firms as Dow Chemicals and DuPont, either because they were economically unviable or because they were environmentally unsound.

Union Carbide, the world's largest producer of ethylene glycol, used its own process captively and did not license it. Scientific Design, which did not have a stake in the final market, licensed its process aggressively and now has the largest share of built capacity. The other major player, Shell, both used and licensed its own process. Recently, Union Carbide has also started to license its technology in a highly selective way. It is important to emphasize

\footnotetext{
${ }^{3}$ Economic theory suggests that tacit collusion is more likely when there are few symmetric firms. Although tacit collusion is assumed away in our theoretical framework, its inclusion would imply that aggressive licensing occurs when there are many technology holders with heterogeneous stakes in the product market, an implication that has the same flavor as our Hypotheses 1 and 2 .
} 
the role of Scientific Design, which was the source of the technology, but not an active producer of the final product. The firm was not inhibited by concerns over its production position or by potential competition from new players. Its behavior has precipitated more proactive licensing strategies by Shell and Union Carbide-companies that may otherwise have shown greater concern for their market shares. Consequently, the industry structure of the ethylene glycol market is highly fragmented, with many players and strong competition in most regions of the world.

\section{THEORY DEVELOPMENT AND HYPOTHESES}

A licensing contract is the less integrated, more market-based alternative allowing firms to profit from their innovation. In fact, licensing is positioned at the extreme of a continuum of governance structures ranging from a market mechanism to hierarchy, i.e., in-house exploitation of the innovation (Williamson, 1991).

The standard framework for analyzing licensing decisions is provided by transaction costs theory. This approach suggests that, given an absence of significant contracting hazards, an arm's-length contract such as licensing would be the most direct way to capture profits from a firm's intellectual asset, such as a process or an idea. However, writing and executing a reliable contract for the use of technology requires adequate specification of property rights, monitoring, and enforcement of contractual terms - any of which may be problematic. Teece (1988) identifies three major sources of transaction costs in technology transfer: (a) incomplete contracts that leave either party open to opportunistic behavior by the other; (b) transaction-specific investments that can give rise to switching costs and 'lock-in' problems; and (c) leakages of valuable proprietary information to potential competitors.

One weakness of the transaction costs theory in its analysis of licensing decisions is its narrow focus around isolated transactions (Williamson, 1999: 1102). Each transaction is treated as an independent item, bearing almost no relationship to previous or future transactions or with the rest of the firm's activities (Argyres and Liebeskind, 1999; Nickerson, Hamilton, and Wada, 2001). If interaction effects are missed or if holistic consequences are glossed over, transaction costs theory would suggest that licensing is chosen when the transaction costs of using a market-based mechanism for profiting from innovation are sufficiently small (Teece, 1988). However, a licensing agreement might not take place, in spite of low transaction costs, if it does not fit within the firm's overall strategy because of negative effects on other sources of revenues that outweigh the profits from the transaction. The net balance is the important variable in deciding whether to license or not. This argument suggests that, rather than focusing on economizing at the level of single transactions, it is advisable to consider the effects of technology licensing on the whole value chain (i.e., economizing at the level of the firm): technology management cannot be performed in isolation from other value-creating activities, such as production or distribution.

\section{Revenue effect vs. profit dissipation effect}

Below, we develop a framework that accounts for these subtleties and allows us to predict empirically the rate of technology licensing among firms. Our approach does not substitute the extant transaction costs theory, but rather complements it. We still argue that, other things held constant, smaller transaction costs stimulate licensing. One should bear in mind that the following discussion focuses on technology licensing and omits any reference to product licensing.

Licensing decisions result from the interplay of two effects that licensing generates on the licensor's profits: the profit dissipation effect and the revenue effect (Arora and Fosfuri, 2003). The revenue effect is the present value of the flows of money accruing to the licensor in the form of licensing payments, net of all possible transaction costs that bear on the seller of the technology. It is the revenue effect on which firms focus when striking a licensing deal. ${ }^{4}$ In the words of one of Dow's vice-presidents, 'by both licensing and using the technology we could generate more cash ....' The revenue effect is positively related

\footnotetext{
${ }^{4} \mathrm{We}$ are ignoring the possibility that licensing might be due to strategic reasons like the blockading of entry (Gallini, 1984) or in order to select competitors (Rockett, 1990). Most importantly, in industries with strong network externalities, licensing may be a way to set and control industry standards (Shapiro and Varian, 1998).
} 
to the gross profits that the licensee can extract from the licensed technology, negatively related to the transaction costs, and positively related to the bargaining power of the licensor. As predicted by the transaction costs theory, therefore, other things held constant, larger transaction costs imply a smaller revenue effect and, in turn, make licensing a less attractive strategy (Teece, 1986). Needless to say, transaction costs, bargaining power, and gross profits earned by the licensee are functions of other variables. For instance, the licensor's bargaining power increases with the strength of intellectual property rights protection and with the number of suitable licensees.

The profit dissipation effect is the reduction in the licensor's profits (i.e., all profits other than payments from the licensing agreement) that might occur as a consequence of an additional firm competing in the product market or of an existing firm becoming more aggressive. ${ }^{5}$ Additional competition in the downstream market can reduce the price-cost margin and/or erode market share. As a result, a licensor that also competes in the product market may encounter a reduction in the profits from directly producing and commercializing the final good. The danger of increased competition in the licensor's own market is echoed by industry players and is often reported as the main reason for not licensing out: 'For our main chemical products, such as epoxy and polyketones, we just don't want to license them out because it would threaten our market' (a Shell spokesperson).

Although the licensor has many strategies to limit the extent of this latter effect (for instance, the contract may impose quantity restrictions or exclusive territories or unit royalties may be set to control the licensee's output), an entrant is nevertheless a potential threat to the licensor. For instance, Hill et al. (1990) report the case of RCA, which once licensed its color TV technology to a number of Japanese companies for exclusive exploitation in Japan. The Japanese companies quickly assimilated RCA's technology, however, and used it to compete directly with RCA in the U.S. market.

The profit dissipation effect depends on several factors, primary among them being the magnitude

\footnotetext{
${ }^{5}$ Technology licensing might allow the entry of a firm that is currently outside the relevant market or might increase the efficiency of an incumbent firm when the licensor transfers its low-cost production technology. In both cases, competition in the product market is likely to increase.
}

of the competitive pressure exerted by a new player in the downstream market. It is the careful comparison between the profit dissipation effect and the revenue effect that explains whether a firm is licensing or not, and, if it does, how much it is licensing.

\section{The role of competition in the market for technology}

Let us consider a situation in which the profit dissipation effect dominates the revenue effect. This is typically the case of a monopolist in both the product and the technology market. In the absence of any threat in the market for technology (i.e., no other sources for the technology), the firm would optimally decide not to license. The presence of another producer (the licensee) would certainly put some pressure on the price that will fall below the monopoly level. Unless other reasons are introduced, the firm could not earn greater profits licensing than not licensing. We are implicitly assuming here that the demand for the final product is stable and that the incumbent monopolist has already made the necessary investment in order to satisfy such demand. Now suppose that another firm has developed the technology to produce the final product and can potentially license it to an entrant. For the sake of simplicity, assume that this potential licensor cannot produce the product itself. For instance, in the chemical industry, many process technologies are licensed by specialized engineering firms that have no stake in the product market and focus their business model around the design, engineering, licensing, and sometimes the construction of chemical plants (Arora, Fosfuri, and Gambardella, 2001). Now assume that a potential entrant exists - one that needs a license to enter the market. What is the most plausible scenario if the monopolist does not license its technology? The potential entrant could strike a deal with the other technology owner and ultimately compete with the monopolist in the product market. As a result, the monopolist might suffer both eroded market share and reduced price-cost margin. Moreover, the monopolist does not collect any licensing payment because it has opted not to license its technology. In other words, the monopolist would have suffered from the profit dissipation effect in any case; but at least it would have benefited from the revenue effect, had it licensed out its technology to the potential entrant. 
The argument would stand unchanged if the perspective licensee were a higher-cost incumbent seeking a more efficient production technology. The key assumption here is that all potential licensors have functionally equivalent technologies. Indeed, a company with proprietary lowcost production technology might still not want to license out its technology, despite the presence of multiple players that license similar but less efficient technology. However, the main idea remains unchanged: weaker competition in the market for technology implies less incentive to license, other things held constant.

When a market for technology exists, as is typically the case for most chemical process technologies, a technology holder's refusal to license will not block entry into the product market, because the prospective licensee can obtain the technology from other potential licensors. Hence, the presence of multiple sources for a technology creates a strategic incentive to license.

However, we do not expect the relationship between the rate of technology licensing and the number of potential technology suppliers to be monotonic everywhere. There are at least two arguments to suggest that, after a certain threshold, the rate of technology licensing might actually decrease as the number of potential technology suppliers increases. First, the number of potential licensees for a given process technology is bounded. In some cases, in fact, the search for suitable licensees turns out to be a long and costly process (Contractor, 1981). If the number of potential licensees is fixed and bounded and the number of potential licensors keeps increasing, at a certain point, the number of effective licenses per licensor will hit the constraint. After that, a further increase in the number of potential licensors produces a reduction in the average number of licenses. Second, a larger number of technology suppliers means stronger competition in the market for technology. Licensors have weaker bargaining power $v i s$-à-vis the prospective licensees. In other words, the revenue effect tends to be competed away when the number of potential licensors increases. When payments from licensing are insufficient to cover transaction costs, firms stop licensing.

In sum, the presence of multiple sources for a technology tilts the balance between the profit dissipation effect and the revenue effect. Some competition in the market for technology makes profit dissipation considerations less important, sparking more aggressive licensing behavior. However, very strong competition in the market for technology annihilates the revenue effect, which, in turn, makes licensing less appealing.

By combining the various arguments, we can formulate the following hypothesis:

Hypothesis 1: There exists an inverted-U shaped relationship between the rate of technology licensing and the number of potential technology suppliers.

In industries in which standards play a crucial role, firms may license aggressively because they would like their technology to be widely diffused. This alternative argument would also predict a positive relationship between the rate of technology licensing and the number of competing technologies. Battles over standards are more important early in the product life cycle (Teece, 1986). Because we focus empirically on mature chemical products with well-established markets, we partially control for that possibility. However, one should be cautious about interpreting empirical findings.

\section{Market share}

We focus here on the direct effect of the licensor's market share in the product market on its incentives to license, all other variables left unchanged. We analyze only the impact of market share on the profit dissipation effect, because the revenue effect is unrelated (at least directly) to market share. As noted previously, the profit dissipation effect is the erosion of profits due to additional competition in the product market. Hence, we claimed that a technology holder licenses if the net licensing revenues are greater than the loss in profits due to increased competition in the product market. Although all incumbent producers potentially lose from the increased competition, each licensor only internalizes the negative effect on its own profits. The smaller the profits the licensor obtains from direct production prior to licensing, the smaller this negative effect. This implies, in turn, that other things equal, firms with smaller market shares have stronger incentives to license, as they suffer from a much smaller profit dissipation effect. This argument can best be understood by fixing the quantity produced by each firm and assuming that entry simply reduces the price-cost margin. Firms that sell larger quantities, i.e., firms 
with larger market shares, would suffer most from competition because the same reduction in the margin is multiplied by a higher volume of sales. Therefore, firms that center their business model on the pure supply of technology with no stakes in the product market have stronger incentives to license than do established producers that enjoy large market shares. This argument is exemplified by the various ways in which BP Chemicals has approached the acetic acid and polyethylene businesses. In acetic acid, BP has strong proprietary technology and a substantial market share. It licenses selectively, typically granting a license only in order to obtain access to markets it would otherwise be unable to enter. In contrast, BP's market share in polyethylene is small. Although it has good proprietary technology in polyethylene as well, there are many other sources of technology for making polyethylene. Thus, BP has licensed its polyethylene technology aggressively, competing with Union Carbide, the market leader in licensing polyethylene technology. We can therefore state the following hypothesis:

\section{Hypothesis 2: The higher the licensor's share in the product market, the smaller its rate of technology licensing.}

A key assumption behind our argument is that market share is independent of other firm-specific variables. However, market share is likely to be positively correlated with the licensor's stock of such complementary assets as distribution or manufacturing. A large endowment of complementary assets better insulates the licensor from the potential competition exerted by the licensees, thereby reducing the profit dissipation effect. However, the presence of a strong competitor reduces the licensees' expectations of future profits and, hence, their willingness to pay for the technology. The revenue effect shrinks as well, possibly offsetting the reduction in the profit dissipation effect. In addition, a larger market share might be due to a more efficient technology. Because the technology is more valuable, the licensor can extract a larger payment from the licensees. However, the licensor is also likely to face reduced competition in the market for technology, thereby having fewer incentives to license out its technology. As we argued above, this second effect is likely to dominate. Finally, a larger market share might be associated with a greater ability to extract rent from the licensees - because of stronger bargaining power in licensing negotiations, for instance-thereby increasing the revenue effect. This correlation is likely to mitigate the negative relationship between the rate of technology licensing and market share, as stated in Hypothesis 2.

We acknowledge the possibility that anticipated market share, i.e., the potential market share the licensor expects to gain, may sometimes be more important than current market share in driving licensing decisions. This possibility can be easily tested, however: current market share should not show up significant in the empirical analysis.

\section{Product differentiation}

Product differentiation implies that the price elasticities of demand for different varieties are not infinite at equal prices. Product differentiation is due to both tangible features (e.g., size, reliability, durability, or safety) and intangible features (e.g. image, status, or esthetic considerations). For the argument we develop below, the important factor is that product differentiation is technology-specific rather than firm-specific. We assume that two firms using identical technology would produce indistinguishable varieties of the product. By contrast, two firms using different technologies would produce differentiated varieties. ${ }^{6}$ Hence, product differentiation is due to differences in the process technology rather than to simple branding. In turn, this feature fits quite well with most chemical products in our database-like ammonia, acetic acid, polypropylene - in which the major source of differentiation is the technology (e.g., type of catalyst, temperature, feedstock) rather than the firm.

The role of technology-specific product differentiation is better understood by focusing on the profit dissipation effect alone. Let us do the following thought experiment. Consider the market for polyethylene, and assume that Mitsui, with its own proprietary technology, competes in the downstream market with several other producers. Assume that Mitsui has a 2 percent market share. Let us start with the case in which the final product, polyethylene, is perfectly homogeneous across

\footnotetext{
${ }^{6}$ If product differentiation is also firm-specific, the profit dissipation effect would shrink because licensor and licensee do not compete head to head. Hence, greater firm-specific product differentiation would imply more licensing. However, the correlation between technology-specific product differentiation and the rate of technology licensing would be qualitatively unchanged.
} 
all producers. Mitsui is a small player and, as we argued above, would not suffer undue loss if an additional firm were to step in and start producing polyethylene. Hence, the profit dissipation effect for Mitsui is relatively small and could well be smaller than the revenue effect. Mitsui might have strong incentives to license. Even if Mitsui has a good proprietary technology, in fact, it might be difficult for the firm to gain a larger share of the polyethylene market. Licensing is a quick and relatively risk-free alternative for accomplishing this task.

Now, consider the opposite situation, in which each producer has a well-defined market niche. In other words, the polyethylene market is highly differentiated and each firm, because of its idiosyncratic technology, is producing its own not-easilysubstitutable variety. Although Mitsui is a small player in the overall polyethylene market, it is almost a monopolist in its niche. Licensing would create much stronger competition in this case, as Mitsui would allow the entry of another firm using the same technology and producing the same variety. The profit dissipation effect is much larger, and the firm might not find it profitable to license. In addition, other technology suppliers are less of a threat because, even if they license, they would not allow direct entry into Mitsui's own market niche. This reasoning leads to the following hypothesis:

Hypothesis 3: The higher the degree of technology-specific product differentiation, the smaller the firm's rate of technology licensing.

\section{METHODOLOGY AND DATA}

We hypothesize that the rate of technology licensing is generated by the function $y=f(x, \beta)$, where $y$ is licensing counts, $x$ is a vector of explanatory variables that include those identified in our hypotheses (plus all available control variables), and $\beta$ is a vector of parameters to be estimated. Because the dependent variable is discrete and non-negative, with numerous zero entries, conventional linear regression models are inappropriate. The simplest model form to accommodate count data is the Poisson regression model. To guarantee non-negativity of $\lambda$, we model the single parameter of the Poisson distribution function, $\lambda$, as $E[y]=\lambda=\exp (x \beta)$. However, our dependent variable has a variance that is four times larger than its mean, suggesting the presence of overdispersion. If this is the case, although the parameters will be consistently estimated, their standard errors will typically be underestimated, leading to spuriously high levels of significance. To address this problem, we use a negative binomial regression, which provides more efficient estimators (Hausman, Hall, and Griliches, 1984). Another econometric concern is the large number of zero observations. As a robustness check, we estimate an equation using a zero inflated negative binomial regression (Greene, 2000).

Our data on licensing come from Chemintell, a commercial database compiled by Chemical Intelligence Services (Chem-Intell), a division of Reed Telepublishing Ltd, which is a member of the Reed Elsevier Plc Group. Chemintell purports to be comprehensive, covering the entire population of chemical plants in the period under study. Chemintell provides information on over 36,000 plants announced or constructed all over the world in 1980-96, in what is broadly defined as the chemical sector. It also reports, albeit incompletely, information on plants built prior to 1980. The database is organized by plant. It reports the name of the company that ordered the plant, the name of the licensor for that plant (or 'staff' for in-house licensing), the city and country in which a plant is located, the name of the chemical process or the product, the date at which the investment was first reported in the specialized trade press, and other information. For about 40 percent of the plants, Chemintell also reports the total cost of investment in the plant in millions of U.S. dollars; and, for a larger number of the plants, it shows the actual or planned capacity.

To test our hypotheses, we focused on a sample of large chemical firms from developed countries (Western Europe, United States, Canada, and Japan) that had, by the year 1988, more than U.S. $\$ 1$ billion in aggregate sales (Aftalion, 1991). Of this set of firms, only 153 had at least one plant reported in Chemintell. These are the firms we used in our study: 67 U.S., 1 Canadian, 32 Japanese, and 53 European firms. (The complete list of firms is available upon request.) We restricted our attention to this sample of large firms because we had to collect firm-specific variables that our database did not provide. Moreover, the focus of this paper is on the licensing strategies of large corporations, which face the trade-off between revenue effect and profit dissipation effect 
more intensely than do smaller firms. Therefore, the licensing activity of specialized technology suppliers, small firms, and start-ups is omitted from our study.

We look at the rate of technology licensing of our large chemical firms in a sample of 107 products. This sample includes all the most important products in our dataset (as defined by worldwide investment) and accounts for more than half of all plants listed in Chemintell. 'Ammonia' and 'acetic acid' are two examples of such products. Because we selected the products with large worldwide installed capacity, our sample is more representative of bulk chemicals than of specialties. A complete list of products along with their classification in chemical sub-sectors is available upon request.

As a first step, we want to identify the firms that possess technological capabilities in a given product, and that can therefore license to others. Then, we can examine the licensing behavior of these firms, which obviously changes across products. The set of potential licensors of ammonia process technology is different from the set of potential licensors of acetic acid process technology, although the two sets might overlap.

To address this issue, we exploited the richness of our dataset. We split the data into two periods - 1980-85 and 1986-96-using the first period to identify which of our 153 firms possessed technological capabilities in any of our 107 products. As a criterion, we used the fact that the firm in question had either licensed the technology or built a plant in-house, using its own technology. As a sensitivity check, we also considered a different time break: 1980-87 and 1988-96. We also experimented with a more demanding criterion: two plants instead of one. Neither of these manipulations changed the qualitative results. ${ }^{7}$ Finally, we used our second period of 1986-96 to examine the licensing behavior of these firms.

One might wonder why we did not exploit the time dimension of our dataset more efficiently by creating a panel rather than a cross-section averaged over 1986-96. There are three reasons for such aggregation. First, some variables, such as the number of potential licensors or the degree

\footnotetext{
${ }^{7}$ It is important to remind the reader that we are examining the licensing of the process technology used to fabricate a given chemical product. Our dataset does not report product licensing, which is the major subject of transaction in pharmaceuticals, for instance.
}

of product differentiation, vary little from year to year. Second, given the size and timing of the investment in a chemical plant, licensing decisions tend to be correlated to long-term rather than shortterm changes. Finally, and most important, we have few plants licensed by each sample firm per year, which would make our dependent variable highly skewed towards zero (the share of positive observations will be below 3\%).

A final important clarification concerns the geographical definition of the market. Although the chemical industry is dominated by large multinational firms, most chemical products included in our sample are characterized by significant transportation costs relative to their unit value. This is especially true for bulk chemicals - the vast majority of our products - and less so for specialties. ${ }^{8}$ Hence, production tends to take place, with some notable exceptions, close to the final market. ${ }^{9}$ To capture this localized feature of chemical markets and following the partition provided in Chemintell, we have divided the world into seven geographical areas: Africa, Western Europe, Eastern Europe, North America, South America, the Middle East, and South East Asia. As a robustness check, we have tried a finer partition, in which we isolated the big country markets (United States-Canada, China, India, Russia, Mexico) and lumped other countries together using membership in trade blocks (EU, Mercosur, ASEAN) or geographical continuity (Middle East countries, Central European countries). This second partition produced 10 geographical areas. Although every definition of market can be criticized, similarity of results between these two groupings should make us confident about the robustness of our empirical findings.

To summarize, we examine the rate of technology licensing of large chemical firms (indexed by $i$ ), in a set of product markets that are defined

\footnotetext{
${ }^{8}$ In addition, some products are difficult to move because of their specific features. For instance, acrylic acid is highly corrosive to many metals and must be stored in stainless steel-, glass-, aluminum- or polyethylene-lined equipment. Also, many chemical acids degrade over time by polymerization.

${ }^{9}$ In 2002, the share of imports to apparent consumption in the United States was 3 percent for sulfuric acid and pharmaceutical preparations; 3.4 percent for chlorine gas; 21 percent for titanium dioxide; less than 1 percent for oxygen, nitrogen, and carbon dioxide; 1.1 percent for hydrogen; and less than 10 percent for paint products (US Census Bureau at http://www.census.gov). Trade in plastics tends to be higher.
} 
around chemical products (indexed by $j$ ) and geographical areas (indexed by $k$ ).

\section{Variables}

\section{Rate of licensing}

This variable measures the number of licensed plants by firm $i$, in product $j$, and geographical area $k$, over the period 1986-96. As discussed above, only a small subset of our 153 firms has technological competencies in any given product $j$. Moreover this subset tends to change for each product.

\section{Potential licensors}

We want to capture the presence of other sources of technological competencies. In other words, we would like to know how many other firms are capable of supplying the process for producing product $j$. We do so by counting the number of firms (excluding firm $i$ ) that have licensed a given process technology for producing product $j$ in the period 1980-85 or have built a plant in-house using their own technology. This is a good proxy for the number of potential licensors of that technology in the period 1986-96. There are two potential measurement errors that could affect this proxy: (1) some firms may not have been technologically active in the period 1980-85, but can potentially license their technology in the period 1986-96. For instance, they might not have developed technological capabilities until 1985; (2) some firms may have been licensing their technology in the period 1980-85, but could not license in the period 1986-96-because their technology had become obsolete, for instance. Yet the average number of potential licensors is similar in magnitude to the average number of 'real' licensors (i.e., the number of firms that have licensed in the period 1986-96), with a correlation above 0.6. In approximately 40 percent of the cases, the two numbers coincide. In half of the remaining cases, the number of potential licensors is smaller than the number of real licensors, whereas the opposite is true for the rest of our observations. Finally, it is also plausible that this measure varies across geographical areas. The set of potential technology suppliers for polyethylene process technology in the United States may differ from the set of potential technology suppliers in China. There may be geographical idiosyncrasies that render a technology suitable for the economic, legal, and environmental conditions of one area, but unsuitable for another. We have estimated our regressions with the number of potential licensors varying across $j$ and across $j k$. Because qualitative results do not change, however, we only show the latter in order to save space.

\section{Market share}

We compute the market share of firm $i$, in product $j$, and geographical area $k$ as the ratio between the capacity built by firm $i$ in $j k$ and the total capacity in $j k$. Because we did not have access to the market shares of firms in the mid 1980s, we had to reconstruct them using the information on capacity investment provided by our database. Although correlated with sales, installed capacity may not always be a good proxy for sales. However, there are no reasons to believe that the difference between installed capacity and sales is distributed across our sample of firms and products in a way that would bias our findings, although we cannot guarantee that this does not occur.

\section{Product differentiation}

Chemintell does not provide a direct measure of technology-specific product differentiation at the level of the product $j$. To operationalize this variable, we built a principal component of three different proxies. Although each proxy has its weaknesses, we think that our principal component measure captures the variability associated with technology-specific product differentiation. The first proxy, which we believe is the most accurate, is the number of different feedstocks that can be used to fabricate a given product, standardized by the size of the world market of that product. In many cases, different technologies use different feedstocks, and the physical properties of the final product might depend on the specific feedstock employed. The second proxy is computed at the sub-sector level. Chemintell classifies all products in 23 sub-sectors. We use plant counts at the product level to compute a Herfindahl index at the sub-sector level (Sutton, 1991). Our index of product differentiation takes the value of 0 if the sub-sector has homogeneous products and the 
value of 1 if the products are totally differentiated. ${ }^{10}$ Our third proxy of product differentiation is the average cost in U.S. dollars per unit of capacity installed in each product $j$. To compute this measure, we have summed all investments (in U.S. dollars) in a given product and divided by the sum of the installed capacity in the same product. We expect that more homogeneous and basic products are produced in large-scale plants in which the cost per unit of capacity installed is lower. By contrast, more differentiated and sophisticated products are produced in small plants and tend to have, on average, a larger cost per unit of capacity installed.

\section{Control variables}

\section{Demand growth}

This variable measures the growth potential in the demand for chemical plants in product $j$ and geographical area $k$. We use the ratio between the total number of plants constructed in $j k$ during the periods 1991-86 and 1980-85. We expect to observe a positive relationship between the rate of technology licensing and demand growth, as a rising demand relaxes the negative effect on the licensor's profits due to increased competition.

\section{Potential licensees}

The larger the number of potential licensees, the stronger the bargaining power of the licensor and, hence, the larger the revenue effect from licensing. Indeed, Contractor (1981) points out that, in some cases, the search for suitable licensees turns out to be a long and costly process. Hence, we posit a positive relationship between the rate of technology licensing and the number of potential licensees. The number of potential licensees is computed as the number of downstream chemical producers active in product $j$ and geographical market $k$ prior to 1986 . This proxy is likely to underestimate the number of potential licensees,

\footnotetext{
${ }^{10}$ We constructed the differentiation index as follows: $\mathrm{DI}_{m}=$ $\sum_{j=1}^{J}\left(\frac{\text { NBPLANT }_{j m}}{\text { NBPLANT }_{m}}\right)^{2}$, where $m$ refers to the subsector and $j$ to the product. NBPLANT is the number of plants.
}

as it does not account for entry. The next control helps us to partially overcome this limitation. $^{11}$

\section{Set-up costs}

This variable measures the average cost of setting up a chemical plant in product $j$. Larger set-up costs imply that entry into the downstream market is more difficult, thereby limiting the number of potential licensees. Therefore this variable complements our proxy for the number of potential licensees.

\section{Aggregate sales}

We include this variable to control for the effect of firm size on the rate of technology licensing. For instance, larger firms could have stronger bargaining power in the licensing negotiations or better options to profit from their technological competences. We use the natural log of aggregate sales of firm $i$ in 1988 to compensate for skewness (Aftalion, 1991).

\section{Multinational}

This variable complements aggregate sales to control for firm size. Multinational counts the number of different countries in which firm $i$ operates.

\section{$R \& D$ intensity}

For each firm $i, \mathrm{R} \& \mathrm{D}$ intensity captures the ratio between R\&D expenditures and sales in 1988 (Aftalion, 1991). The sign of this variable is not theoretically clear a priori. Higher R\&D intensity means that the firm is more likely to possess valuable technological assets to license out. On the other hand, firms tend to avoid giving away their state-of-the-art technology and typically prefer to license older vintage technologies. However, the reason for including this variable, as well as the aggregate sales and multinational variables, is to control for firm-specific sources of variation that might affect the rate of technology licensing.

\footnotetext{
${ }^{11}$ As a robustness check, we also used the number of downstream chemical producers that were active in geographical market $k$ at the subsector level. This variable accounts for potential entry by diversification. Results do not change qualitatively.
} 


\section{Transaction costs}

Our theory suggests that the greater the transaction costs, the smaller the revenue effect and, in turn, the smaller a firm's rate of technology licensing. Therefore we must control as well as we can for different sources of transaction costs. We use the following variables. Experience is a dummy variable that takes the value of 1 if firm $i$ has undertaken at least one licensing deal prior to 1986 in product $j$ and geographical area $k$. Experience in gathering information about prospective licensees, negotiating, and writing and enforcing contracts lowers the cost of licensing. Experience is therefore a good proxy for the transaction costs of licensing. We posit that, by reducing transaction costs, experience makes licensing a more appealing strategy. Patents reports the total number of patents granted at the U.S. Patent Office during the period 1976-95 to the technology used to fabricate product $j$. As several authors have noted (e.g., Teece, 1988; Von Hippel, 1994), patents are more likely to be issued for technologies in which the underlying knowledge is sufficiently codifiable. Process technologies that have been granted few patents are more likely to rely on trade secrecy and are, hence, less likely to be transferred through contracts. Finally, we use a set of dummy variables for chemical sectors to help us to control for sector-specific differences in transaction costs. For instance, some chemical sectors may have better legal protection of intellectual property, thereby reducing transaction costs. Chemintell classifies all products into nine broad sectors: Oil Refining, Petrochemicals, Minerals and Metallurgy, Plastics and Rubber, Inorganic Chemicals, Agriculture, Gas, Organic Chemicals, and Miscellaneous. ${ }^{12}$

\section{Dummy variables for geographical areas}

This set of dummy variables is meant to control for sources of heterogeneity across locations. Some areas could have better conditions for technology licensing - better access to related technological services that make the transaction easier, for instance.

\footnotetext{
${ }^{12}$ As mentioned above, Chemintell also provides a finer classification of products into 23 chemical subsectors.
}

\section{Dummy variables for licensor nationality}

This set of dummy variables helps to control for cross-country heterogeneity in the attitude towards licensing.

Table 1 reports the means, standard deviations, and correlations among the dependent, independent, and control variables. The table employs our first definition of geographical market in which the world is divided into seven areas.

\section{EMPIRICAL RESULTS}

Table 2 shows the results of the negative binomial regressions using Chemintell's partition of the world in seven geographical areas. Table 3 shows the same regressions for our second definition of geographical markets. As a robustness check, we have also performed Poisson estimations. Results, available from the author upon request, are similar to those reported here. However, the overdispersion parameter in the negative binomial regressions is significantly different from zero, thus reinforcing our conjecture that the Poisson distribution is inappropriate.

Model 0 omits the core covariates, showing only the baseline model with the control variables. Models 1 and 2 differ only in the definition of market share. Whereas Model 1 reports the market share at the level of the product-geographical area, Model 2 shows the worldwide market share at the product level. Our discussion above suggests that, for many chemical products, production tends to take place close to the final market; thus Model 1 is our preferred specification. An LR test comparing the sparser specification (Model 0) with the augmented models (Models 1 and 2) suggests that our main explanatory variables play a significant role on top of the controls.

There are 1748 observations in Table $2 .{ }^{13}$ Hypothesis 1 predicts that the rate of technology licensing is first increasing and then decreasing in the number of potential technology suppliers. To test this hypothesis, we add a square term to the number of potential licensors. If our hypothesis is correct, we should obtain a positive coefficient for the number of potential licensor and a negative coefficient for the square term. The parameter

\footnotetext{
${ }^{13}$ As we have explained above, we have a highly unbalanced panel: 153 firms, 107 products and seven geographical areas would total more than 100,000 observations in a balanced panel.
} 


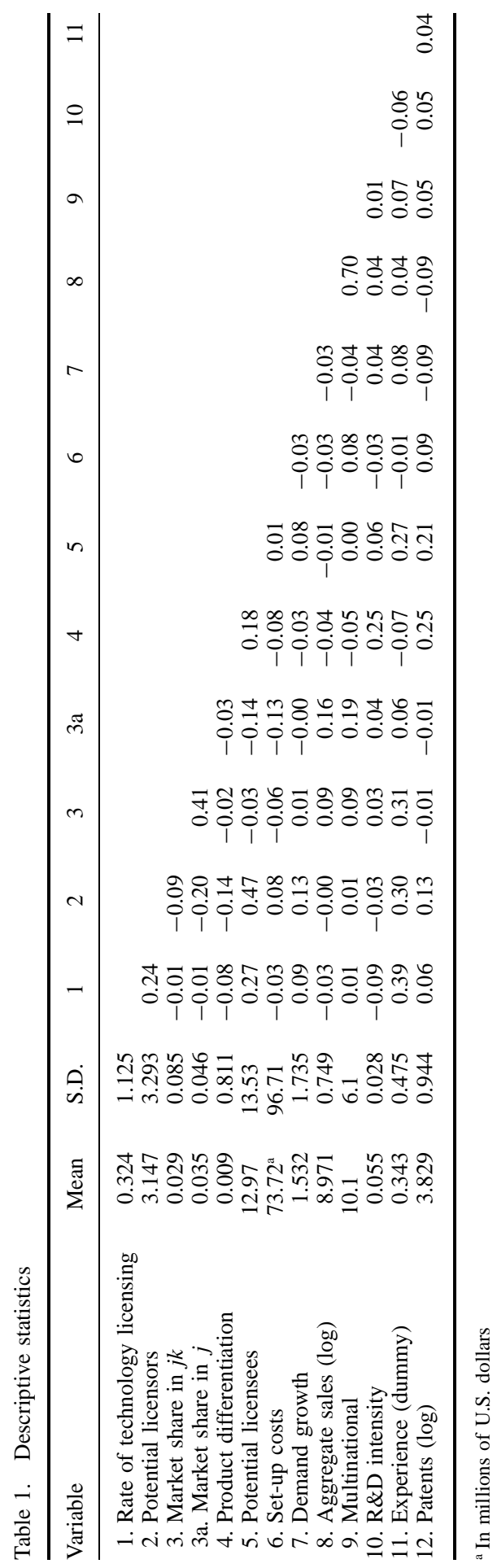


Table 2. Rate of technology licensing by firm $i$ in product $j$ and geographical area $k$ (seven geographical areas)

\begin{tabular}{lcccc}
\hline Variable & \multicolumn{3}{c}{ Negative binomial } & $\begin{array}{c}\text { Zero-inflated } \\
\text { model }\end{array}$ \\
\cline { 2 - 4 } & Model 0 & Model 1 & Model 2 & \\
\hline Constant & $-3.544^{* * *}$ & $-5.124^{* * *}$ & $-4.587^{* * *}$ & $-3.465^{* * * *}$ \\
Potential licensors & & $0.140^{* * *}$ & $0.164^{* *}$ & $0.159^{* * * *}$ \\
Square term & & $-0.012^{* * *}$ & $-0.013^{* * *}$ & $-0.013^{* * *}$ \\
Market share in $j k$ & $-6.506^{* * *}$ & & $-6.496^{* * *}$ \\
Market share in $j$ & & & $-5.609^{* * *}$ & \\
Product differentiation & & $-1.011^{* * *}$ & $-1.006^{* * *}$ & $-1.154^{* * *}$ \\
Controls & & & & \\
Potential licensees & $0.037^{* * *}$ & $0.037^{* * *}$ & $0.041^{* * *}$ & $0.036^{* * * *}$ \\
Set-up costs & -0.001 & $-0.002^{*}$ & $-0.002^{*}$ & 0.002 \\
Demand growth & $0.097^{* *}$ & $0.080^{* *}$ & $0.091^{* * *}$ & $0.072^{*}$ \\
Log of aggregate sales & -0.131 & -0.070 & -0.103 & -0.063 \\
Multinational & 0.010 & 0.019 & 0.019 & -0.028 \\
R\&D intensity & $-7.671^{* *}$ & $-6.162^{* *}$ & $-6.749^{* * *}$ & $-8.703^{* * *}$ \\
Experience & $4.253^{* * *}$ & $4.283^{* * *}$ & $4.171^{* * *}$ & $3.499^{* * *}$ \\
Patents & -0.008 & 0.036 & 0.013 & -0.066 \\
Dummy variables for chemical sectors & Yes & Yes & Yes & Yes \\
Dummy variables for geographical areas & Yes & Yes & Yes & Yes \\
Dummy variables for licensor nationality & Yes & Yes & Yes & Yes \\
Number of observations & 1748 & 1748 & 1748 & 1748 \\
Log-likelihood & -790 & -757 & -768 & -742 \\
Chi-squared & 623 & 689 & 667 & 135 \\
\hline & & & & \\
\hline
\end{tabular}

${ }^{*} p<0.1 ;{ }^{* *} p<0.05 ;{ }^{* * *} p<0.01$

estimate for the number of potential licensors is positive and highly significant in all specifications reported in Table 2 . We also find a negative and significant coefficient for the square term, suggesting that the relationship between the rate of technology licensing and the number of technology suppliers displays an inverted-U shape. By using Model 1, for instance, one can show that the inflection point is around 6 (notice that the number of potential licensors varies between 0 and 17 , with an average of about 3). If all other variables are kept at their mean value, moving from no potential licensors to 5 potential licensors would imply an increment in the rate of technology licensing of about 50 percent.

Hypothesis 2 predicts that firms license more in product markets where they have smaller market shares. Indeed, as we argued above, the profit dissipation effect is positively correlated to market share. The sign of the parameter estimate for market share in Model 1 is negative and highly significant. If all other variables are kept at their mean value, moving from a 5 percent market share to a 10 percent market share would reduce the rate of technology licensing by about 40 percent. In Model 2, we use as a regressor the worldwide market share in product $j$. Although the coefficient is still negative and significant, we observe a smaller magnitude and a much larger standard deviation. As an additional robustness check, we have also run a regression, using only the observations in which firm $i$ has a non-zero market share. Indeed, the decision to license by a firm with existing facilities in the market might be a quite different decision from that made by a firm with zero market share. Qualitative results remain unchanged, although coefficients display larger standard deviations, due to the reduced number of observations.

Hypothesis 3 suggests that firms show a higher rate of technology licensing when the product market is sufficiently homogeneous. We used as a measure of technology-specific product differentiation a principal component extracted from three proxies. The coefficient is negative and significant, suggesting that technology licensing is less likely to occur in a differentiated product market. This finding seems to support Hypothesis 3. Keeping all other variables at their mean value, a standard 
Table 3. Rate of technology licensing by firm $i$ in product $j$ and geographical area $k$ (10 geographical areas)

\begin{tabular}{lcccc}
\hline Variable & \multicolumn{3}{c}{ Negative binomial } & $\begin{array}{c}\text { Zero-inflated } \\
\text { model }\end{array}$ \\
\cline { 2 - 4 } & Model 0 & Model 1 & Model 2 & \\
\hline Constant & -1.901 & $-3.622^{* * *}$ & $-3.576^{* * *}$ & $-3.920^{* * *}$ \\
Potential licensors & & $0.363^{* * *}$ & $0.369^{* * *}$ & $0.306^{* * *}$ \\
Square term & & $-0.030^{* * *}$ & $-0.030^{* * *}$ & $-0.028^{* * *}$ \\
Market share in $j k$ & $-2.992^{* *}$ & & $-6.716^{* * *}$ \\
Market share in $j$ & & & -0.243 & \\
Product differentiation & & $-0.981^{* * *}$ & $-0.940^{* * *}$ & $-1.231^{* * *}$ \\
Controls & & & & \\
Potential licensees & $0.053^{* * *}$ & $0.036^{*}$ & $0.036^{*}$ & 0.044 \\
Set-up costs & $-0.003^{* * *}$ & $-0.003^{* * *}$ & $-0.003^{* * *}$ & $0.003^{* *}$ \\
Demand growth & $0.254^{* * *}$ & $0.290^{* * *}$ & $0.292^{* * *}$ & $0.080^{*}$ \\
Log of aggregate sales & -0.157 & -0.102 & -0.103 & 0.093 \\
Multinational & $0.038^{*}$ & $0.040^{*}$ & 0.036 & 0.001 \\
R\&D intensity & $-8.837^{* * *}$ & $-7.854^{* *}$ & $-7.690^{* * * *}$ & $-10.512^{* * *}$ \\
Experience & $0.794^{* * *}$ & $0.718^{* * *}$ & $0.717^{* * *}$ & $0.360^{* * *}$ \\
Patents & 0.021 & 0.072 & 0.055 & 0.136 \\
Dummy variables for chemical sectors & Yes & Yes & Yes & Yes \\
Dummy variables for geographical areas & Yes & Yes & Yes & Yes \\
Dummy variables for licensor nationality & Yes & Yes & Yes & Yes \\
Number of observations & 2294 & 2294 & 2294 & 2294 \\
Log-likelihood & -970 & -949 & -951 & -917 \\
Chi-squared & 274 & 316 & 312 & 122 \\
\hline
\end{tabular}

$* p<0.1 ;{ }^{* *} p<0.05 ; * * *<<0.01$

deviation increase in the level of product differentiation would reduce the rate of technology licensing by 40 percent. As a robustness check, we have also entered our three proxies separately as measures of product differentiation. Results (not included) are qualitatively similar to the ones reported in Table 2.

The signs of the other variables are reasonable. Particularly interesting is the positive and highly significant coefficient of the number of potential licensees in a given product market $j k$. A larger number of licensees creates greater bargaining power for the licensor. It also means that the licensor is much more likely to find a licensee that better suits the idiosyncrasies of the licensor's technology. In turn, this implies that the value generated from the transaction is higher, making licensing a more appealing option. Additionally, the average set-up cost for a chemical plant in product $j$ has a negative impact on the rate of technology licensing, thereby confirming that larger investment costs reduce the demand of technology. Demand growth has the positive expected sign, significant in all regressions. The findings seem to support the idea that higher transaction costs reduce the rate of technology licensing. Indeed, our dummy for experience in licensing in product $j$ and geographical area $k$ is positive and highly significant. However, the coefficient of the number of patents is not statistically different from zero. This finding is not surprising, in light of Cohen, Nelson, and Walsh's (2000) results; they found that patents are not good instruments for protecting process innovations. Our measures of firm size are not significant, whereas R\&D intensity is negative, implying that firms with less $R \& D$ intensity have a higher rate of technology licensing.

As we discussed in the previous section, one important econometric concern is the presence of a large number of zeros in our dependent variable. We have controlled for this potential problem through a zero-inflated negative binomial regression (Greene, 2000). A zero-inflated negative binomial model, also known as hurdle model, assumes that the zeros are generated by a different process from the remaining counts. A binary probability model determines whether a zero or a nonzero outcome occurs; then, in the latter case, a (truncated) negative binomial distribution describes the positive outcomes. All 
our explanatory variables have been used in the binary probability regression-except for the sector, nationality, and geographical area dummies, which we omitted because of convergence problems in the estimation. Results for the (truncated) negative binomial distribution are shown in the last column of Table 2. All variables of theoretical interest maintain their sign and significance. A positive Vuong test shows that the inflated model performs slightly better than the standard negative binomial model. Moreover, many of the coefficients in the binary probability model are not statistically significant, which may imply that many zeros simply stand for the impossibility to license, and do not capture the deliberate outcome of a firm's decision.

Table 3 reports our findings using the finer partition of the world into the 10 geographical areas described above. It is comforting to see that all variables keep their sign unchanged, although some coefficients display larger standard deviations. This suggests that our results are robust to different definitions of geographical markets. Model 2 additionally confirms our conjecture that the relevant market share is at the product-geographical area level, and not worldwide.

\section{CONCLUSION, DISCUSSION, AND IMPLICATIONS}

There is increasing evidence that firms in some sectors hope to profit from their intellectual property not merely by embodying it in their own output, but also by licensing it to others, including potential competitors. Licensing does, however, entail a trade-off: licensing revenues must be balanced against the lower price-cost margin and/or reduced market share implied by increased competition from the licensees. In this paper we argued that competition in the market for technology could trigger more aggressive licensing behavior. Indeed, the trade-off between profit dissipation effect and revenue effect that normally guides licensing decisions should be adjusted for the presence of rival licensors. In particular, when there are multiple technology holders, they not only compete in the product market; they also compete in the market for technology. Because licensing partially substitutes for production, firms lacking adequate downstream commercialization (production and marketing) capabilities are naturally more aggressive licensors. Moreover, we have argued that increasing product differentiation, when driven by differences in the technologies, not only softens price competition in the product market, but also reduces the rate of licensing in the technology market.

We tested this framework using an extensive dataset on worldwide investment in chemical plants. We examined licensing strategies by the use of a sample of large chemical producers in more than 100 products. Our results suggest that the presence of a market for technology plays a crucial role in creating incentives for a more proactive licensing behavior. Firms that normally would have not licensed their technology might be forced to do so because of the competitive pressure in the market for technology.

Two contributions are particularly worth emphasizing here. First, this research underscores the crucial role of a market for technology in shaping firms' licensing strategy. This finding has implications both for the literature that has addressed the rationales behind a firm's decision to license (Gallini, 1984; Rockett, 1990; Anand and Khanna, 2000a) and for the literature on innovation and technology exploitation (Teece, 1986; Gans et al., 2002). In the former case, our paper suggests that in some industries it might be problematic, if not wrong, to analyze a firm's licensing strategy in isolation, abstracting from product and technology market dynamics. Indeed, most of this literature has assumed that the licensor is a monopolist technology holder, implying that the analysis of all potentially interesting interactions in the market for technology have not been considered. In the latter case, our paper offers an approach better suited to understanding a firm's rate of technology licensing rather than the extant transaction costs framework, although we still claim that transaction costs are important, ceteris paribus. Second, and perhaps most important, our paper provides one of the few large-scale studies of the determinants of the rate of technology licensing. This contribution is particularly valuable in light of the recent trend towards a more widespread use of licensing agreements for the exploitation of the firm's intellectual property.

Our study has several limitations. From an empirical point of view, our database did not provide any measure of technology-specific product differentiation, forcing us to use proxies. Although we believe that these proxies represent the missing 
measure accurately, there is room for improvement. Ideally, this measure should capture the difference between the product produced with a firm's own process technology and the products fabricated by other incumbents. In this case, our empirical analysis could benefit from additional data collection, which might require an in-depth analysis of all process technologies available for each of our 107 products. In addition, although our theory predicts that stronger competition in the market for technology generates additional incentives to license because it changes the trade-off between the profit dissipation effect and the revenue effect, other explanations might generate similar findings. For instance, if standard setting is important, firms might license aggressively because they would like to have their technology widely diffused (Shapiro and Varian, 1998). Although we focus on mature product markets in which standards battles are less crucial, empirically disentangling this alternative explanation is not easy. Hence, the interpretation of our findings should be made with caution. Theoretically our framework would clearly benefit from a deeper integration of our strategic positioning approach with the transaction costs approach. Ideally, one should be able to predict simultaneously the choice of the governance structure and the extent to which each governance structure is used. Finally, as far as it concerns the generality of our findings, one could easily contend that they are idiosyncratic to the chemical industry. As a partial defense to our work, we could point to empirical evidence showing that industries with large licensing activity, such as electronics, biotechnology, and semiconductors, are also those that have sufficiently well-functioning markets for technology (Arora et al., 2001). However, only future research can demonstrate whether our findings are industryspecific or more generally applicable.

From a more applied point of view, our study suggests that firms exploiting licensing opportunities must ensure that the trade-off between licensing revenues and rent dissipation is well managed. First of all, this requires a close coordination between the various activities in the firm's value chain. Technology management cannot be performed in isolation from other value-creating activities such as production, distribution, and sales. Second, it becomes crucial to educate business managers about the net value added from sale of products vs. that from licensing. Licensing revenues are rarely comparable to the revenues from sales of products, but the cost of generating a dollar of licensing revenues is significantly lower than the cost of generating a dollar of product sales. Finally, it requires that managers have incentives consistent with those of the firm as a whole. Managers who are rewarded for sales growth or market share will tend to overlook licensing opportunities.

A final cautionary remark is needed. The recent enthusiasm by many industry practitioners and independent consultants about the virtue of licensing might, in some cases, be misplaced. Licensing, especially when triggered by the presence of a market for technology, is a double-edged sword. Although some firms may benefit from aggressive licensing, the final outcome is likely to be increased competition in the product market and lower overall industry profits. Attempts to implicitly or explicitly collude in the licensing market, which are relatively common in the history of the chemical industry, confirm the relevance of this argument.

\section{ACKNOWLEDGEMENTS}

I would like to thank Ashish Arora, Isabel Busón, Julio de Castro, Bronwyn Hall, Raffaele Oriani, Thomas Rønde, Giovanni Valentini, Oliver Williamson, two anonymous reviewers, and seminar participants at the 2003 Annual Meeting of the Academy of Management (Seattle), University Pompeu Fabra, Carnegie Mellon University, Copenhagen Business School, Sant'Anna School of Advanced Studies, Jornadas de Economía Industrial (Granada), University of Valencia and University of Zaragoza for helpful comments and suggestions on a previous draft. I gratefully acknowledge financial support from the European Commission (HPSE-CT-2002-00146), and the Spanish Ministry of Science and Technology (SEC2003-03797). The usual disclaimer applies.

\section{REFERENCES}

Aftalion F. 1991. History of the International Chemical Industry. University of Pennsylvania Press: Pittsburgh, PA.

Anand BN, Khanna T. 2000a. The structure of licensing contracts. Journal of Industrial Economics 48(1): 103-135.

Anand BN, Khanna T. 2000b. Do firms learn to create value? The case of alliances. Strategic Management Journal 21(3): 295-315. 
Argyres NS, Liebeskind JP. 1999. Contractual commitments, bargaining power, and governance inseparability: incorporating history into transaction cost theory. Academy of Management Review 24(1): 137-145.

Arora A. 1997. Patent, licensing and market structure in the chemical industry. Research Policy 26: 391-403.

Arora A, Ceccagnoli M. 2006. Patent protection, complementary assets, and firms: incentives for technology licensing. Management Science 52: 293-308.

Arora A, Fosfuri A. 2003. Licensing the market for technology. Journal of Economic Behaviour and Organization 52: 277-295.

Arora A, Fosfuri A, Gambardella A. 2001. Markets for Technology: Economics of Innovation and Corporate Strategy. MIT Press: Cambridge, MA.

Cohen WM, Nelson RR, Walsh JP. 2000. Protecting their intellectual assets: appropriability conditions and why U.S. manufacturing firms patent (or not). Working paper 7552, National Bureau of Economic Research, Cambridge, MA.

Contractor FJ. 1981. International Technology Transfer. D.C. Heath: Lexington, MA.

Dussauge P, Garette B, Mitchell W. 2000. Learning from competing partners: outcomes and durations of scale and link alliance in Europe, North America, and Asia. Strategic Management Journal 21(2): 99-126.

Gallini NT. 1984. Deterrence through market sharing: a strategic incentive for licensing. American Economic Review 74: 931-941.

Gans J, Hsu D, Stern S. 2002. When does start-up innovation spur the gale of creative destruction? RAND Journal of Economics 33(4): 571-586.

Greene WH. 2000. Econometric Analysis (4th edn). Prentice-Hall: Upper Saddle River, NJ.

Hausman JA, Hall BH, Griliches Z. 1984. Econometric models for count data with an application to the patents-R\&D Relationship. Econometrica 42(4): 909-938.

Hill CWL. 1992. Strategies for exploiting technological innovations: when and when not to license. Organization Science 3: 428-441.

Hill CWL, Hwang LP, Kim WC. 1990. An eclectic theory of the choice of international entry mode. Strategic Management Journal 11(2): 117-128.

Kogut B, Singh H. 1988. The effect of national culture on the choice of entry mode. Journal of International Business Studies 19: 411-432.
Mowery DC, Shane S. 2002. Introduction to the Special Issue on University Entrepreneurship and Technology Transfer. Management Science 48(1): v-ix.

Nickerson JA, Hamilton BH, Wada T. 2001. Market position, resource profile, and governance: linking Porter and Williamson in the context of international courier and small package services in Japan. Strategic Management Journal 22(3): 251-273.

Rigby D, Zook C. 2002. Open-market innovation. Harvard Business Review 80(10): 5-12.

Rivette KG, Kline D. 1999. Rembrandt in the Attic: Unlocking the Hidden Value of Patents. Harvard Business School Press: Boston, MA.

Rockett K. 1990. Choosing the competition and patent licensing. RAND Journal of Economics 21(1): $161-171$.

Shapiro C, Varian HR. 1998. Information Rules: A Strategic Guide to the Network Economy. Harvard Business School Press: Boston, MA.

Sine WD, Shane S, Di Gregorio D. 2003. The halo effect and technology licensing: the influence of institutional prestige on the licensing of university inventions. Management Science 49(4): 478-496.

Sutton J. 1991. Sunk Costs and Market Structure. MIT Press: Cambridge, MA.

Teece DJ. 1986. Profiting from technological innovation. Research Policy 15(6): 285-305.

Teece DJ. 1988. Technological change and the nature of the firm. In Technological Change and Economic Theory, Dosi G, Freeman C, Nelson R, Silverberg G, Soete L (eds). Pinter: London; 256-281.

The Economist. 2005. A market for ideas. 20 October: $48-51$.

Tullo AH. 2003. The next wave. CENEAR 81: 26-27.

Von Hippel E. 1994. 'Sticky information' and the locus of problem solving: implications for innovation. Management Science 40(4): 429-439.

Williamson OE. 1991. Comparative economic organization: the analysis of discrete structural alternatives. Administrative Science Quarterly 36(4): 269-296.

Williamson OE. 1999. Strategy research: governance and competence perspectives. Strategic Management Journal 20(12): 1087-1108. 